\title{
Research on Role and Effectiveness of Three-Dimensional Creative Painting in Business Promotion Activities
}

\author{
Xiaofei Qiu \\ Address:School Of Design Of JiangHan University, WuHan, HuBei, China \\ Email:65801599@qq.com
}

Keywords: Three-Dimensional Creative Painting, Role, Effectiveness

\begin{abstract}
Continuous economic development and constantly improve people's living standards, demand for living space by practicality, comfort aptitude economic, cultural and personal change, living space have higher requirements, aesthetics has undergone tremendous changes. 3D dimensional painting its unique creative approach, modeling tools and loved by the people, artistic wall painting popular in recent years, not only because it meets the needs of the people of fashion personality, but also a way of saving environmentally friendly low-carbon design. In 3D dimensional painting interior space significantly affect the overall effect, decorative effect, strong visual impact, but also to meet the people's personality, fashion pursuit of living space. With the development of 3D stereoscopic constitutes art teaching in the field of advertising design has also been a profound effect. Thus the birth of many three-dimensional advertising, the advertising industry plays an important role for improving advertising environment has made great contributions indelible.
\end{abstract}

\section{Introduction of Three-Dimensional Creative Painting}

$3 \mathrm{D}$ creative painting the name suggests, this is the street ground plane as carrier, the use of optical illusions, combined with a certain artistic techniques by creating a virtual three-dimensional spatial effect of painting, drawing objects are often realistic, image, three-dimensional, delicate, so the viewer often feel a sense of real ones artistic effects, and with the picture viewer to interact, resonate, generating publicity shock.

Typically, three-dimensional paintings in three forms: all pictures are painted on the ground called painting; all pictures are painted on the wall called the mural; partially painted on the ground and another portion of the wall paintings called the wall painting. These three ways according to the specific needs of the actual painting places geography and achieve $t$ creative he desired effects to choose. 3D paintings usually drawn process: In the first pre-determined to produce three-dimensional picture of the inquest and photographed places on the spot as a reference, and then eradicate terrain size and location of which will be just the right program based sauce. Process to draw attention to the screen at any time the details for continuous correction until it is completed. In the late three-dimensional paintings also show the picture properly post-maintenance, ready to respond to the canvas thermal expansion and contraction due to weather problems ${ }^{[1]}$.

In addition, three-dimensional painting drawing materials mainly based on picture sediment determined, usually with two cloth sediment dilute paint or oil paint; floor sediments with acrylic paints or toner. But it is difficult to draw Toner Save, propylene draw directly on the floor is difficult to clean, it is generally more choice of three-dimensional paintings drawn on canvas painting techniques used both for display safe and environmentally friendly two dilute pigments. In order to adapt to the commercialization and electronic information development model needs to meet the three-dimensional painting is easy to preserve in commercial activities, demolition fast, multi-reuse characteristics, body painting is also much more expensive than the first computer to draw a good image before adopting inkjet print production the way. 


\section{Art Features of three-dimensional painting}

3D dimensional painting was finally able to feel the stereoscopic paintings, in addition to know the principles of painting and drawing skills outside, but also by means of optical illusion to achieve the intended purpose. 3D three-dimensional painting is a visual difference between the two through visual illusion that is to pass information to the viewer. However, this optical illusion is conditional, must meet certain conditions 3D dimensional painting to achieve the desired effect ${ }^{[2]}$. Fig.1 shows the street three-dimensional painting.

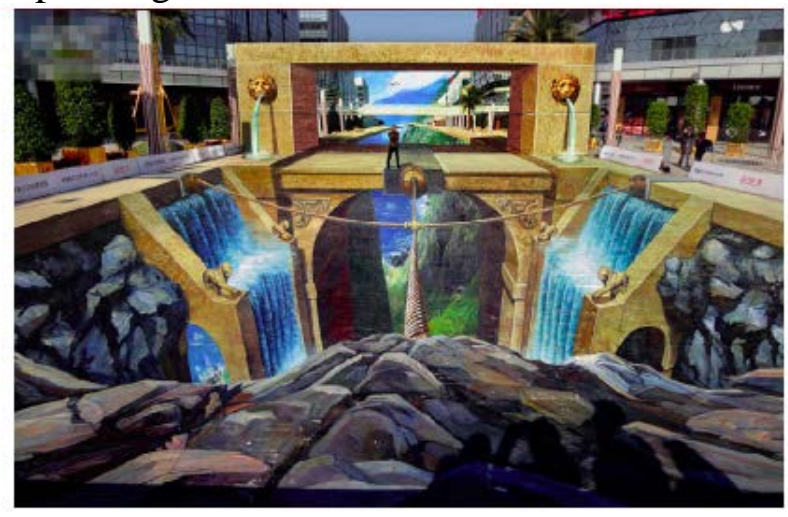

Fig. 1 The street three-dimensional painting

Art comes from life, 3D three-dimensional painting is by exaggeration, generalization, distortion and other artistic techniques to people, animals and other original shape, through permutations and combinations to create a new visual image. 3D three-dimensional painting style and diverse, realistic, impressionistic, cartoons and other artistic styles, forms are very diverse. A wide variety of forms, enriching the interior space, but also add life to the fun. 3D dimensional painting has a strong expressive and interesting, full of personal expression that people can have unlimited reverie. 3D three-dimensional painting can draw anywhere, at any desired pattern shape, pattern, artistic, elegance and vitality, both the furniture and the environment fit and embellishment, but also make the space more coordinated and personalized.

One of the outstanding features is its 3D dimensional painting itself has a decorative, ornamental said here, including the two characteristics, first modeling and manifestations, 3D stereoscopic paintings from the composition to the shape, colors visual plane reached from other paintings decorative effect. The second feature is mainly drawn from the $3 \mathrm{D}$ form and internal analysis, the main purpose of dialogue is to become decorative art and human connection between the wall paintings. The reason why 3D painting become a trend in the moment, and today's young people a unique, assertive a 3D dimensional painting decorative, creativity and interior space and easier with color, highlighting the distinctive taste. This is the 3D three-dimensional picture of the unique characteristics of fashion. 3D dimensional painting quite creative, reflect the personality, based on the character designs adds a mysterious effect ${ }^{[3]}$.

\section{Stereo Effect of Static Screen 3D Painting}

General painting is done on a flat art, and it is generally a certain painting has planarity. Painting is a static nature of aesthetic activity, so active objects are non-dynamic lines, colors and so on. Painting of daily life or mind imagined some specific things, these things in mind and daily life activities may be, may be stationary, but in the plane finished paintings, the only stationary.

In Chinese painting aesthetics history, from ancient times to pursue both form and spirit are prepared, the pursuit of a static dynamic, and strive to show the infinite in finite static dynamic in. Chinese painting to show the charm of this painting called "Yiping," "Kamijina." Sheikh mentioned in Paintings Six Approaches "paintings products recorded", in which the first method is the "Lively." From Gu kaizi "Vivid" to Song "not shape" and just thinking quite similar, indicating that 
the pursuit of meaning inherent aesthetic tendencies growing development. Fig. 2 shows the static screen 3D painting.
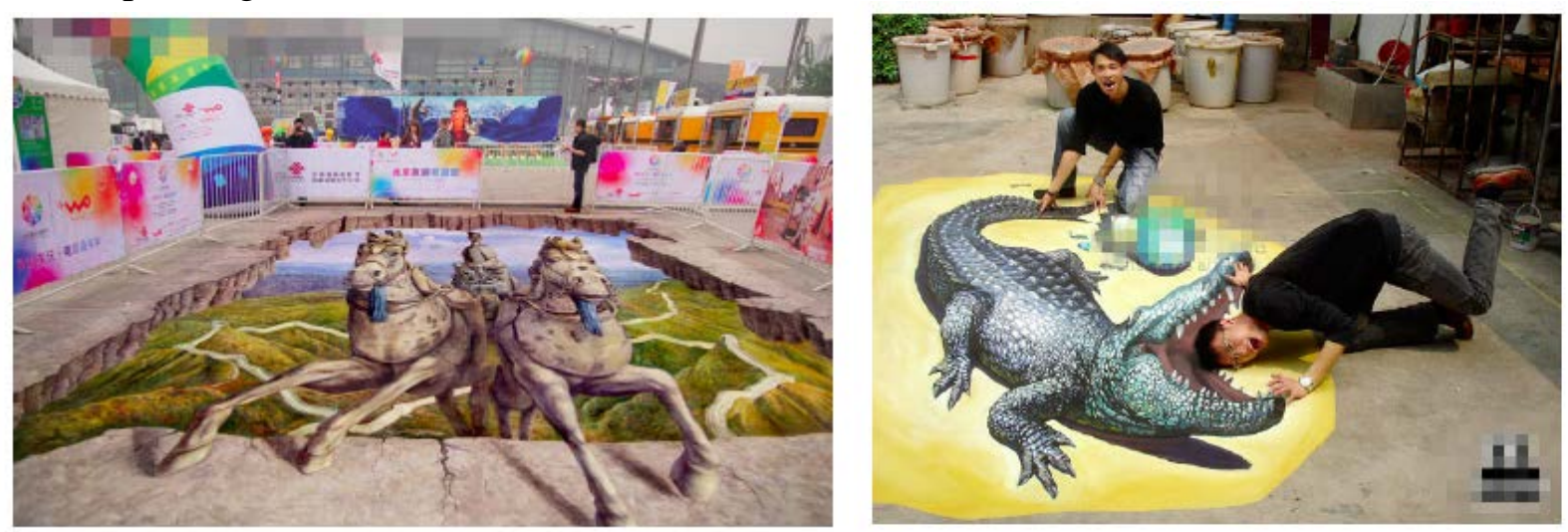

Fig. 2 The static screen 3D painting

In order to operate as a three-dimensional thinking, three-dimensional space, three-dimensional constitution is essentially different in the way of thinking, and graphic composition, color composition. It follows the basic principles of the theory of the constitution, the object is to split the point, line, surface, and then combined into a random coincidence form process. Thus, the longer vivid paintings, it is still on a flat surface. 3D painting, the painting belongs to the category of large, 3D painting to this earth plane as painting the place, and generally the same painting, with flat and static at the same time, they have a difference with the general painting. 3D painting artists strive to perfect combination of plane and solid, and strive in a limited static, dynamic show the infinite, both for 3D painting plane presence on the ground, but also three-dimensional presence in the aesthetic subject's eyes ${ }^{[4]}$.

\section{Application of 3D Dimensional Painting}

3D three-dimensional street painting as irresistible a strong visual impact, while the advertising industry after being referenced application and conference, opening ceremony, opening normal street advertising, a number of large corporations would stereoscopic 3D street painting for commercial advertising. Realistic effects, highly detailed pixels, the operation of arbitrariness, short production cycle, the advantages of the majority. Super eye appeal make 3D street advertising can help enhance the visibility and brand value.

The study found three-dimensional perspective of the specified wrong stadium advertising design advertising compared with the general sense of perspective, the strengths are: first, rational use of space, increase advertising information dissemination. In a limited space to maximize the amount of advertising to enhance dissemination of information, increase public access to information on the frequency of a given ad. Second, reduce advertising costs. Optical illusion is a two-dimensional image constructed three-dimensional effect of technology, we will be able to get the desired three-dimensional ads on inexpensive materials, without the use of real three-dimensional advertising material cost as high cost, and the corresponding relocation maintenance costs are greatly reduced. Third, help strengthen the advertising visual effects, the audience received advertisement information to improve the odds ${ }^{[5]}$. Fig.3 shows the sporting events three-dimensional painting.
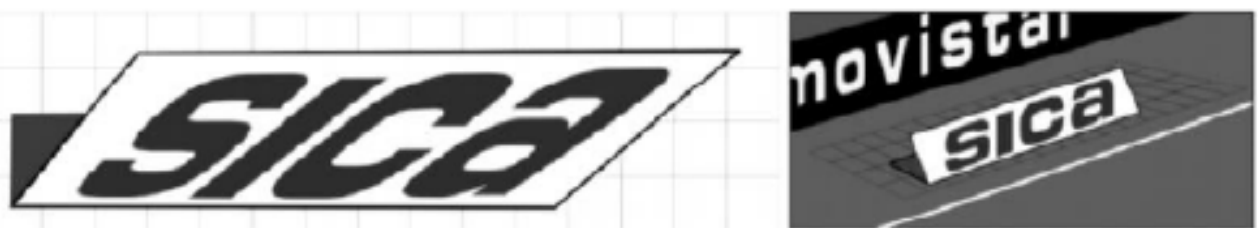

Fig. 3 The sporting events three-dimensional painting 
3D three-dimensional design is the use of human visual illusion in a two-dimensional plane to create a three-dimensional picture, and this new innovative approach strengthens the powerful print ads propaganda effect. Domestic call 3D street advertising graphic design of diverse, 3D street advertising dimensional painting, 3D three-dimensional ad painting, 3D street advertising painting, street advertising painting, 3D street advertising painting, street advertising dimensional paintings, three-dimensional street advertising to draw, street advertising to draw three-dimensional, three-dimensional city posters, posters and other three-dimensional city. Fig.4 shows the shopping mall three-dimensional painting.
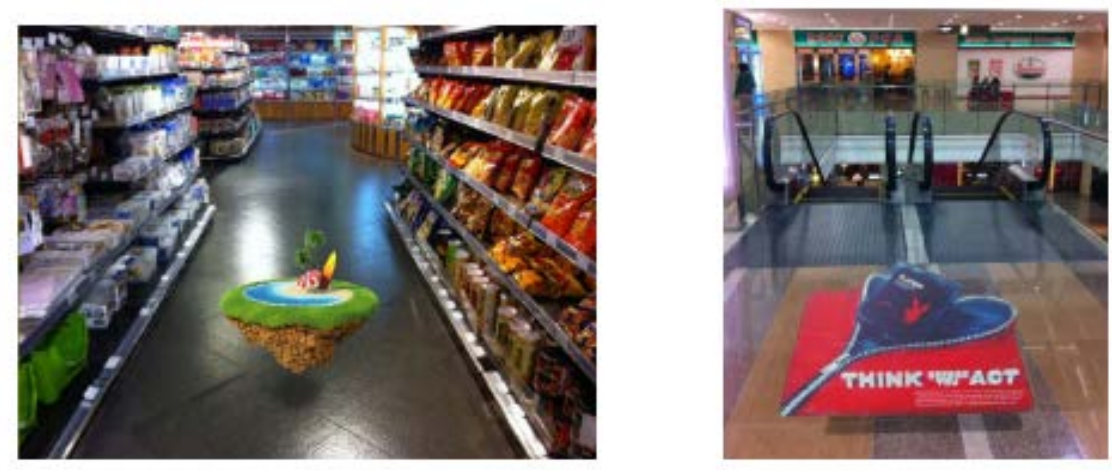

Fig. 4 The shopping mall three-dimensional painting

\section{Conclusions}

Dimensional painting as a comprehensive art, contains a wealth of theoretical basis, technical approach and artistic expressions, the use of visual illusion of space docking gimmicky, 3D three-dimensional wall paintings take advantage of binocular stereo vision, the simulation on a two-dimensional plane three-dimensional effect, you will see a very wonderful world. 3D painting want to be fully integrated into public life, it is necessary to allow more contact with the viewer, know and love it. This need to promote social forces requires more artists' greater investment and effort. 3D dimensional painting designs are gradually into people's vision, in line with the aesthetic trends of today. Repetitive, overly conventional three-dimensional paintings have been tired, under diverse social backgrounds, personalized design show even more of its cultural identity.

\section{References}

[1] Hu Qiaomu. 《Encyclopedia of China, art》 [M]. Encyclopedia of China Publishing Hous, 1993.

[2] Wang qi. "Color optical illusion applied research in graphic design [D], Shanghai Jiaotong University, 2008 (1).

[3] Du Meijia. "Hand-painted wall painting decorative beauty and practical beauty" [J]. Art theory, 2009. 10.

[4] Shen xin, Zou Dan, Qi Xinghua three-dimensional painting of new human visual art [J] Beijing: Civilization, 2010 (12).

[5] Qu jing, most suitable onlookers 3D painting [J]. Environment and Life, 2012 (4) . 